\title{
From Norway Spruce Bark to Carbon Foams: Characterization, and Applications
}

\author{
Toni Varila, ${ }^{\mathrm{a}, \mathrm{b}}$ Hanna Brännström, ${ }^{\mathrm{c}}$ Petri Kilpeläinen, ${ }^{\mathrm{d}}$ Jarkko Hellström, ${ }^{\mathrm{e}}$ Henrik Romar, ${ }^{\mathrm{a}}$ \\ Juha Nurmi, ${ }^{c}$ and Ulla Lassi ${ }^{\mathrm{a}, \mathrm{b}}$
}

\begin{abstract}
Fresh bark from spruce Picea abies was milled and extracted with hot water. The extracts were purified in a number of steps in order to get tannin-extracts pure enough to prepare tannin-based carbon foams. The chemical composition of the extracts were analyzed. The foams were maturated and thermally treated to obtain desired properties, such as specific surface area, porosity, and compressive strength. It was possible to produce carbon foams even if they contained carbohydrate impurities. Differences in the properties of the carbon foams such as compressive strength, specific surface areas, and pore size distributions might be related to the compositions of the extracts. The foams were finally activated chemically and physically and were tested in adsorption of methylene blue. Results from the adsorption tests showed that adsorption was highly related to the total pore volume and the amount of mesopores created inside the foam structure during the thermal treatment.
\end{abstract}

Keywords: Biomass; Spruce; Bark; Extractives; Tannins; Carbon foams

Contact information: a: Research Unit of Sustainable Chemistry, University of Oulu, P.O. Box 8000, FI90014, Finland; b: Applied Chemistry, University of Jyvaskyla, Kokkola University Consortium Chydenius, P.O. Box 567, FI-67101 Kokkola, Finland; c: Natural Resources Institute Finland (Luke), Teknologiakatu 7, FI-67100 Kokkola, Finland; d: Natural Resources Institute Finland (Luke), Tietotie 2, 02150 Espoo, Finland; e: Natural Resources Institute Finland (Luke), Humppilantie 7, FI-31600 Jokioinen, Finland; *Corresponding author: toni.varila@chydenius.fi

\section{INTRODUCTION}

Substantial amounts of forest biomass are consumed in Nordic countries. In 2018, this volume amounted to $78.2 \mathrm{Mm}^{3}$ in Finland (Torvelainen 2019). The accumulation of by-products, such as bark, is significant in the debarking process of wood. For example, the amount of spruce bark generated at mills in Finland is 0.8 to $1.2 \mathrm{Mt} / \mathrm{a}$ (d.m.), calculated with an estimated average dry density of $380 \mathrm{~kg} / \mathrm{m}^{3}$ (Kemppainen 2015). Bark is currently primarily used in producing heat and power or in landscaping (Feng et al. 2013); however, spruce bark is a rich source of important polyphenolic extractives and natural antioxidants, such as tannins and stilbenes (Krogell et al. 2012), and these compounds have the potential to be utilized in high-value applications. Tannins can be defined as polyphenolic compounds presented in plant structure, where they are bonded to the cores of polyol, flavan-3-ol (catechin) or triterpenoid units (Khanbabaee and van Ree 2001).

Tannins are usually water-soluble polyphenols that differ from most other natural phenolic compounds in their ability to precipitate proteins from solution (Scalbert 1991). Some high-molecular-weight tannins or tannins complexed with proteins or polysaccharides may be water-insoluble. Due to the existence of a variety of tannin molecules, they are divided into 3 categories, as presented in Fig. 1, proanthocyanidins, commonly known as condensed tannins, hydrolyzable tannins, or phlorotannins. 
Condensed tannins (CT), are oligomers made of polyhydroxyflavan-3-ol units, which can differ in their hydroxylation pattern (Bianchi et al. 2014). In European softwood and hardwood species, they are largely procyanidins with varying proportions of the 3-flavanol units catechin and epicatechin (Holmbom 2011). The main sources of commercially produced condensed tannins are the bark of black wattle (Acacia mearnsii) and quebracho heartwood (Schinopsis balansae and S. lorentzii) (Bianchi et al. 2014; Holmbom 2011). However, extraction of pine and spruce bark has been shown to give economical yields of CTs. (Lacoste et al. 2015) Furthermore, CTs in quebracho and wattle are predominantly profisetinidins and prorobinetidins (Pash et al. 2001) with a resorcinol type A-ring while spruce CTs have essentially a phloroglucinol type A-ring, i.e. they are mostly procyanidins and to some extent prodelphinidins. Phloroglucinol type A-ring is much more reactive towards formaldehyde than a resorcinol type counterpart (Pizzi 2008), indicating that spruce bark could be an excellent source of high quality CTs for wood adhesive industry.
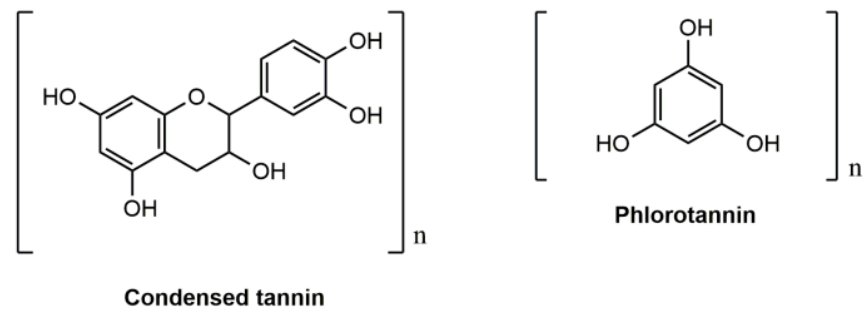

Phlorote

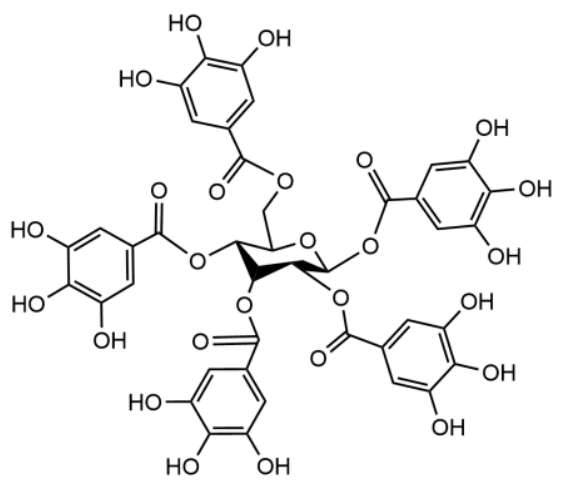

Hydrolyzable tannin

Fig. 1. Main structural units of different tannin types. Letter $n$, after the square brackets, indicates that a number of monomers are attached to the condensed tannin and phlorotannin polymer.

When planning the whole process chain for the production of extractives-based chemicals, there are multiple aspects that need to be considered, starting from the raw material acquirement. This is the reason that many initial extractives suitable for potential raw material applications are either rather volatile or chemically unstable (Alén 2000). The extractives content starts to decrease immediately after tree felling (Assarsson et al. 1963; Ekman 2000). All the phases of the wood handling process and the duration of each of the phases in the procurement chain, as well as environmental conditions, are important with respect to changes in extractives content and composition. This needs to be taken into account when aiming at the development of new valuable extractives-based bio-chemicals.

The growing demand of nature-derived ingredients to replace synthetic chemicals, and the search for the green and sustainable extraction methods, has initiated new research and developments in the field of plant extraction (Royer et al. 2012; Pfennig et al. 2011; Chemat et al. 2013). Recent trends in extraction techniques have largely focused on finding solutions that minimize the use of organic solvents. Thermolability of the molecules should be taken into account when choosing the extraction method. This also means that temperature and other extraction parameters should be optimized (De Monte et al. 2014). In general, extractions can be facilitated by increasing the temperature to favor solubilization and diffusion (Seidel 2012; Zhang et al. 2018). However, the presence of thermolabile compounds sets limits for extraction temperature, as too high temperatures 
may cause decomposition of these compounds. Another disadvantage of high extraction temperature is that it may lead to extracts of undesirable impurities and solvent losses. There is also optimum time range for the duration of extraction. While the contact time between solvent and solid material must be sufficient to allow mass transfer to properly take place, increasing time will increase the extraction efficiency only to a certain point (Pfennig et al. 2011; Zhang et al. 2018). Increasing time does not have an effect after the equilibrium of the solute is reached inside and outside the solid material. Here the aim was to produce the tannins by an eco-friendly extraction process; thus hot-water extraction was the chosen extraction technique.

Extraction of plant biomass typically leads to a mixture of components in the resulting extract (Pfennig et al. 2011). For this reason, several treatment steps are required after extraction. Typically these include: filtration to separate solids, concentration of extracts by evaporation of solvents, enrichment of target components (e.g., by liquid-liquid extraction, chromatography, membrane separation, and crystallization), removal of impurities like heavy metals by complexation, or polyaromatic hydrocarbons by adsorption technologies, and drying of products and product forming technologies for solid extracts (e.g., spray drying, granulation, etc.). The choice of concentration and purification steps has an influence on energy usage and the life cycle of tannin production (Ding et al. 2017). Adsorbents such as XAD4 (hydrophobic polyaromatic), XAD7HP (aliphatic acrylic crosslinked polymer), XAD761 (phenol-formaldehyde), XAD1180 (hydrophobic polyaromatic), XAD16N (Cross-linked polyaromatic), and FPX66 (cross-linked polyaromatic) have been used to purify blueberry tannins (Buran et al. 2014) and juice pomace (Sandhu and Gu 2013).

Leather tanning and winemaking together with applications within the building material sector dominate and drive a growing international tannin market (Grand View Research 2017). CTs are also used as a component in adhesives. More recently, the use of tannins in rigid insulating foams has been demonstrated (Link et al. 2011).

Carbon foams (CF) can be produced in a number of ways using polyphenolics such as lignin or tannins as building blocks. In many of these foam structures, formaldehyde is used as a crosslinking agent between individual -OH groups (Tondi et al. 2009; Tondi and Pizzi 2009). Due to the high toxicity of formaldehyde, there has been intensive research for replacing reactions. One of these formaldehyde-free routes to produce carbon-foams is to polymerize tannins in a catalytic reaction using furfuryl alcohol as a crosslinking agent. (Link et al. 2011)

Previously only pre-cleaned tannin powders with a high degree of purity have been used in the foaming as described earlier by Celzard et.al. (2010). Similarly, in an earlier study (Varila et al. 2019) the authors successfully produced CF using purified tannin acid as a reagent. The novelty of the present study is that the whole process chain from native spruce bark over pre-treatment, extraction, extract cleanups to the production of tanninbased CF is described. Finally, the extracts are used to produce CF, which are thermally maturated and activated into activated $\mathrm{CF}$ and tested in adsorption of methylene blue.

\section{EXPERIMENTAL}

Fresh Norway spruce bark (Picea abies) was provided by UPM-Kymmene Oyj Pietarsaari sawmill on February 15, 2019 for the extractions. The logs had come from clear cut stands of various origins. They were debarked with a rotor debarker at UPM Pietarsaari 
mills. The sample material was retrieved from the debarker bin immediately after it had been peeled off the logs. All material was in a frozen state, as sampling took place in the middle of the winter season. Some $15 \mathrm{~m}^{3}$ of bark was loaded in a truck and transported to Luke's Kannus terminal for screening.

For the $\mathrm{CF}$, purified extractives from spruce bark were kindly delivered by Luke (Natural Resources Institute Finland). Furfuryl alcohol (98\%) and the surfactant polyoxyethylenesorbitan trioleate (brand name Tween 85) were ordered from Acros Organic. The catalyst, p-toluenesulfonic acid monohydrate (PTSA, 99\%), and the blowing agent (n-pentane, 99.4\%) were ordered from Merck KGaA (Darmstadt, Germany). For the chemical activation, technical grade $(97 \%) \mathrm{ZnCl}_{2}$ was ordered from VWR Chemicals (Helsinki, Finland).

\section{Pretreatment of Bark and Extraction of Tannins}

A $4 \mathrm{~m}^{2}$ screen with $20 \times 20 \mathrm{~mm}$ mesh size was used to remove fines from the sawmill bark. This was done in order to minimize the risk of flow restrictions in the extraction chamber. A total of $431 \mathrm{~kg}$ of acceptable fresh bark material was produced. Of this mass, 20 random samples were taken for determination of bark, moisture, and ash contents. Based on these samples the bark material was found to contain $97.3 \%$ (standard deviation, $\mathrm{SD}=1.1$ ) bark, the rest being sapwood. This inclusion of wood is unavoidable, as the bonding between wood and inner bark is very strong in winter months. The emphasis of industrial debarking is to produce bark-free logs and not wood free bark. The moisture content of the bark fraction was $63.2 \%(s=0.61)$ and ash content $3.3 \%(s=0.03)$.

The accepted fraction was used as a feedstock in pressurized hot water extraction (PHWE). Spruce bark was utilized as soon after debarking as possible to guarantee a reasonable extraction yield in the pilot-scale process. A 10 day time-lapse took place prior to extraction, during that time the material was stored in cold, ambient winter conditions.

Spruce bark samples were extracted using a $300 \mathrm{~L}$ hot water extraction system (Kilpeläinen et al. 2014). The samples were extracted with hot water in batch mode. Two extractions were conducted with $39 \mathrm{~kg}$ oven-dried (O.D.) bark (102 kg fresh) in both extractions. Extraction temperatures were $70{ }^{\circ} \mathrm{C}$ for $80 \mathrm{~min}$ and $90{ }^{\circ} \mathrm{C}$ for $40 \mathrm{~min}$. The extraction parameters for pilot scale extractions were determined by analyzing the results from laboratory-scale hot water extraction with ASE (Accelerated Solvent Extractor) using the response surface methodology (results will be published later by Brännström et al.). Tannin extract 1 is from the first extraction at $70{ }^{\circ} \mathrm{C}$ and tannin extract 2 is from the second hot water extraction at $90{ }^{\circ} \mathrm{C}$. Extracts were collected in containers and samples were taken. Samples were frozen and were stored at $-20{ }^{\circ} \mathrm{C}$ in dark. Extraction yields were calculated on a dry bark basis.

\section{Purification of Extracts}

Hot water extracts were purified using $7 \mathrm{~kg}$ of XAD7HP adsorbent (Dow, Chauny, France). The adsorbent was packed in a glass column and washed before use. Hot water extract was transferred to a column and extract was added until nearly the whole adsorbent was reddish. Tannins were then eluted out of column using ethanol as eluent and the ethanol eluents were finally dried using a rotary evaporator. The dried samples of XAD7HP purified extracts are denoted Dried tannin 1 and Dried tannin 2, and the samples are from $70{ }^{\circ} \mathrm{C}, 80$-min and $90{ }^{\circ} \mathrm{C}, 40$-min, hot water extractions, respectively. 


\section{Analytical Methods}

Moisture and ash content of the bark was determined according to the standard methods SFS-EN 14774-2 (2010) and SFS-EN 14775 (2010), respectively. Wood content in the bark fraction was determined according to the standard method SCAN 53:94 (1994). Altogether 20 samples were taken for the determination of wood content.

The amount and composition of sugars and hemicelluloses in extract were determined with acid methanolysis (Kilpeläinen et al. 2014). Acid methanolysis depolymerizes hemicelluloses and pectins and converts sugars to methyl glycosides. Solid samples were treated for $5 \mathrm{~h}$ and extracts for $3 \mathrm{~h}$. Resorcinol was used as an internal standard. Samples were silylated and analyzed with Shimadzu GC-2010 gas chromatograph (Kyoto, Japan) equipped with HP-1 column (25 m length, $0.2 \mathrm{~mm}$ ID and $0.11 \mu \mathrm{m}$ film thickness) and flame ionization detector (FID). Hydrogen was used as a carrier gas.

The amount of polyphenols was determined using Shimadzu UV-Vis spectrometer UV2401PC at $280 \mathrm{~nm}$. The total polyphenolic yield is called tannin yield further on in-text (Ding et al. 2017). Purified industrial tannin, Tannino QL-SOL (Silvateam, San Michele Mondovi, Italy) was used as an external standard and treated the same way as samples. Samples were diluted in $0.1 \mathrm{M} \mathrm{NaOH}$, and UV absorption at $280 \mathrm{~nm}$ was determined.

CT was determined with three analytical replicates of each sample by HPLC after thiolytic degradation according to Mattila et al. (2018). Briefly, samples were weighed (20 to $30 \mathrm{mg}$ ) into $1.5 \mathrm{~mL}$ Eppendorf vials and $1 \mathrm{~mL}$ of depolymerization reagent $(3 \mathrm{~g}$ cysteamine / $4 \mathrm{~mL} 13 \mathrm{M} \mathrm{HCl} / 56 \mathrm{~mL}$ methanol) was added. The vials were sealed and incubated for $60 \mathrm{~min}$ at $65^{\circ} \mathrm{C}$, after which the degradation products, i.e., free flavan-3-ols (terminal units) and their cysteaminyl derivatives (extension units), were determined by HPLC equipped with diode array detection (DAD) and fluorescence detection (FLD).

The analytical pyrolysis of purified and dried extract samples was performed with a foil pulse Pyrola 2000 MultiMatic (Pyrola AB, Lund, Sweden) pyrolyzer coupled to an Agilent 7890B gas chromatograph (Py-GC; Santa Clara, CA, USA). No replicate pyrolysis analyses were conducted. The column was an Agilent HP5-MS capillary GC column (30m $\times 0.25 \mathrm{~mm}$, film thickness $0.25 \mu \mathrm{m})$. Detection was carried out with an Agilent 5977B quadrupole mass selective detector (MSD) with electron impact (EI) ionization. Interpretation of the mass spectra of the pyrolysis products was based on a commercial database, Wiley $10^{\text {th }} / \mathrm{NIST} 2012$. Semi-quantification was done by calculating the relative abundance of each pyrolysis product, i.e., peak area-\% of total peak area. Thermally assisted hydrolysis and methylation ( $P$ y-THM-GC-MSD) was also performed for the samples. For THM-GC-MSD, approximately $500 \mu \mathrm{g}$ of the dried extract was dissolved in $10 \mu \mathrm{L}$ of tetramethylammonium hydroxide $(25 \%$ in methanol), whereafter the solution was added to the $\mathrm{Pt}$ filament and pyrolyzed at $380{ }^{\circ} \mathrm{C}$ for $2 \mathrm{~s}$.

\section{Production of Tannin-Based Carbon Foams}

The tannin-based CF were produced from the purified extracts (tannins) delivered by Luke using the method described earlier by Link et al. (2011). In short, the extracts were added to the mixture of water, surfactant, and crosslinker and mixed thoroughly to make a fine paste. After a homogeneous mixture was obtained, the blowing agent and catalyst are added followed by further mixing. Finally, the resulting solution is mixed and left for foaming overnight in a furnace.

The matured tannin-based CF was cut into pieces. The pieces were inserted into a steel reactor in a tubular oven and treated thermally in a flow of nitrogen gas. Further, some 
pieces were converted into activated $\mathrm{CF}$ by either physical activation (steam activation in an atmosphere of nitrogen) or chemical activation (impregnation with $\mathrm{ZnCl}_{2}$ ) followed by thermal treatment according to the method described previously (Varila et al. 2017).

\section{Specific Surface Area, Pore Volume, Pore Size Distribution}

Specific surface areas (SSA) and pore distributions were determined from the adsorption-desorption isotherms using nitrogen as the adsorbate. Determinations were performed with a Micromeritics ASAP 2020 instrument (Norcross, GA, USA). Portions of each sample (100 to $200 \mathrm{mg}$ ) were degassed at low pressure $(2 \mathrm{~mm} \mathrm{Hg}$ ) and at a temperature of $413 \mathrm{~K}$ for $2 \mathrm{~h}$ in order to clean the surfaces and remove any gas adsorbed. Adsorption isotherms were obtained by immersing sample tubes in liquid nitrogen (-195.8 ${ }^{\circ} \mathrm{C}$ ) to achieve isothermal conditions. Gaseous nitrogen was added to the samples in small doses, and the resulting isotherms were obtained. Specific surface areas were calculated from adsorption isotherms according to the Brunauer-Emmett-Teller (BET) method (Brunauer et al. 1938). Total pore volumes were calculated from the adsorption isotherm at a relative pressure $\left(\mathrm{P} / \mathrm{P}_{0}\right)$ of 0.985 (Seaton et al. 1989) assuming slit-formed pores (Lastoskie et al. 1993).

The pore size distribution (PSD) of pore volumes (vol.\%) was calculated from the individual volumes of micro-pores, meso-pores, and macro-pores with density functional theory (DFT- model) (Seaton et al. 1989) assuming slit-formed pores (Lastoskie et al. 1993). With the instrumental setup used, micro-pores down to $1.5 \mathrm{~nm}$ in diameter could be measured, even if there might have been some contribution from smaller pores. The micropore areas and volumes were calculated by the t-plot using Harkins and Jura (1943) equations. According to previous works, the SSAs were measured with a precision of 5\% (Hackley and Stefaniak 2013).

\section{Compressive Strength of Carbon Foams}

Compressive strengths $(\sigma)$ of foams were determined using a Zwick/Roell Z010 testing machine (Kennesaw, GA, USA) with a load cell of $10 \mathrm{kN}$. The loading speed was $0.1 \mathrm{~mm} / \mathrm{s}$, and the measurement ended when the force decreased by $50 \%$ from maximum or deformation reached 30\%. Compressive strength was calculated with Eq 1.

$$
\sigma=F / A
$$

where $F(\mathrm{~N})$ is the maximum force at the linear region of the compression curve and $A$ $\left(\mathrm{mm}^{2}\right)$ is the surface area. The accuracy of the instrument was $\pm 1 \%$.

The stress-strain curve of cellular material typically has three distinguishable regions: linear part at low strain, a plateau region (collapse of the cell layers), and densification (all cell layers are compressed). The compressive strength can be defined as the value at the plateau whereas the slope of the linear part represents the elastic modulus (i.e., resistance against elastic or non-permanent deformation). The curve roughness

("noise") is a result of the redistribution of the compression after the fracture of layers of cells and subsequent loading of the next cell layers.

\section{Adsorption of Methylene Blue}

The activated carbon (AC) foams were tested for their adsorptive properties using the adsorption of methylene blue (MB) into the pores by the method described in Raposo et al. (2009). In short, a solution containing $1000 \mathrm{mg}$ of $\mathrm{MB}$ per liter $\mathrm{H}_{2} \mathrm{O}$ was prepared. A total of $50 \mathrm{~mL}$ of this solution was transferred into Erlenmeyer flasks $250 \mathrm{ml}$ in volume, 
$50 \mathrm{mg}$ of the AC foam was added, and the solutions were continuously agitated for $48 \mathrm{~h}$ on an orbital shaker to achieve equilibrium between the adsorption and desorption of the test dye. The portions of each solution were filtered and diluted if needed, and the absorbance of the solution was measured at $664 \mathrm{~nm}$ on a Shimadzu UV-Vis $2401 \mathrm{PC}$ double-beam spectrophotometer. The concentration of the solution was calculated from a calibration line obtained with known concentrations of MB. The adsorbed mass was calculated using Eq 2, and the percentage of MB removed was calculated using Eq. 3,

$$
\begin{aligned}
& q(\mathrm{abs})=\left(C_{0}-C_{t}\right) \times(V / m) \\
& \% \text { removed }=\left(C_{0}-C_{t}\right) / C_{0}
\end{aligned}
$$

where $C_{0}$ is the initial concentration of $\mathrm{MB}(1000 \mathrm{mg} / \mathrm{L}), C_{t}$ is the measured concentration after $48 \mathrm{~h}, V$ is the volume of MB solution used, and $m$ is the mass of the AC foam used.

\section{RESULTS AND DISCUSSION}

\section{Results from Extraction and Extract Cleanup}

The amount of collected extracts was $233 \mathrm{~kg}$ and $232 \mathrm{~kg}$. Hot water extracted 111 $\mathrm{mg} / \mathrm{g}$ and $110 \mathrm{mg} / \mathrm{g}$ of spruce bark. Polysaccharide composition of spruce bark and XAD7HP treated dried tannins are presented in Fig. 2.

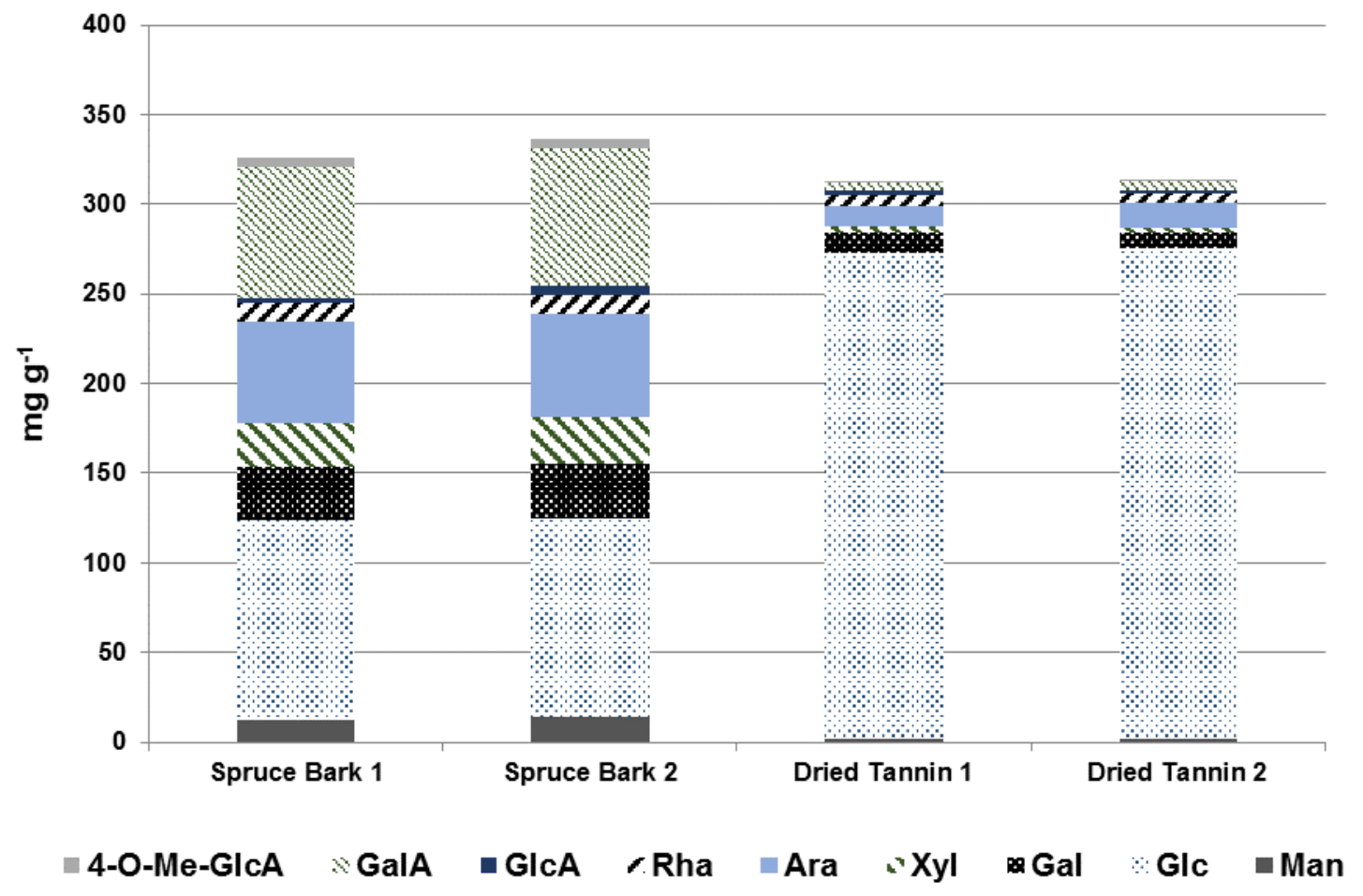

Fig. 2. Non-cellulosic carbohydrate composition of original spruce bark and XAD7HP treated dried tannins. 
The original spruce bark contained mainly glucose, arabinose, and galacturonic acid. Galacturonic acid and rhamnose are from pectins, and there were $84 \mathrm{mg} / \mathrm{g}$ and 87 $\mathrm{mg} / \mathrm{g}$ of pectins in the original barks. Bark contained mannose $12 \mathrm{mg} / \mathrm{g}$ and $14 \mathrm{mg} / \mathrm{g}$ and galactose $30 \mathrm{mg} / \mathrm{g}$ and $31 \mathrm{mg} / \mathrm{g}$ from spruce hemicellulose galactoglucomannan (GGM). Glucose originates from hemicelluloses, inner bark sugars, and glucosides.

Hot water extraction (HWE) removed mainly glucose from the bark. The proportion of other sugars did not change during HWE. XAD7HP treated and dried crude tannins had $313 \mathrm{mg} / \mathrm{g}$ of sugars that were mainly glucose $271 \mathrm{mg} / \mathrm{g}$ and $274 \mathrm{mg} / \mathrm{g}$ consisting of $87 \mathrm{w} \%$ of sugars. Only minor amounts of pectins $9 \mathrm{mg} / \mathrm{g}$ and $10 \mathrm{mg} / \mathrm{g}$ were present in dried tannins. Additionally, only small amount of softwood hemicellulose sugars galactose and mannose, $10 \mathrm{mg} / \mathrm{g}$ and $11 \mathrm{mg} / \mathrm{g}$, respectively, could be found in dried tannin samples.

Dried XAD7HP treated extracts had $554 \mathrm{mg} / \mathrm{g}$ and $670 \mathrm{mg} / \mathrm{g}$ of tannins according to UV280 nm measurement. Tannin yield might include some polyphenols derived from lignin since these compounds have absorption in the same wavelength range. Still, extraction temperatures were relatively low and softwood lignins usually degrade at higher temperatures.

CTs in Norwegian spruce bark composed mostly of (epi)catechins but also (epi)gallocatechins were detected as minor subunits agreeing with previous studies ( Matthews et al. 1997; Bianchi et al. 2014; Hammerbacher et al. 2014) CT content in the bark samples was $3 \%$ of the dry matter (Fig. 3), and the average degree of polymerization was 6.0 to 6.1 .

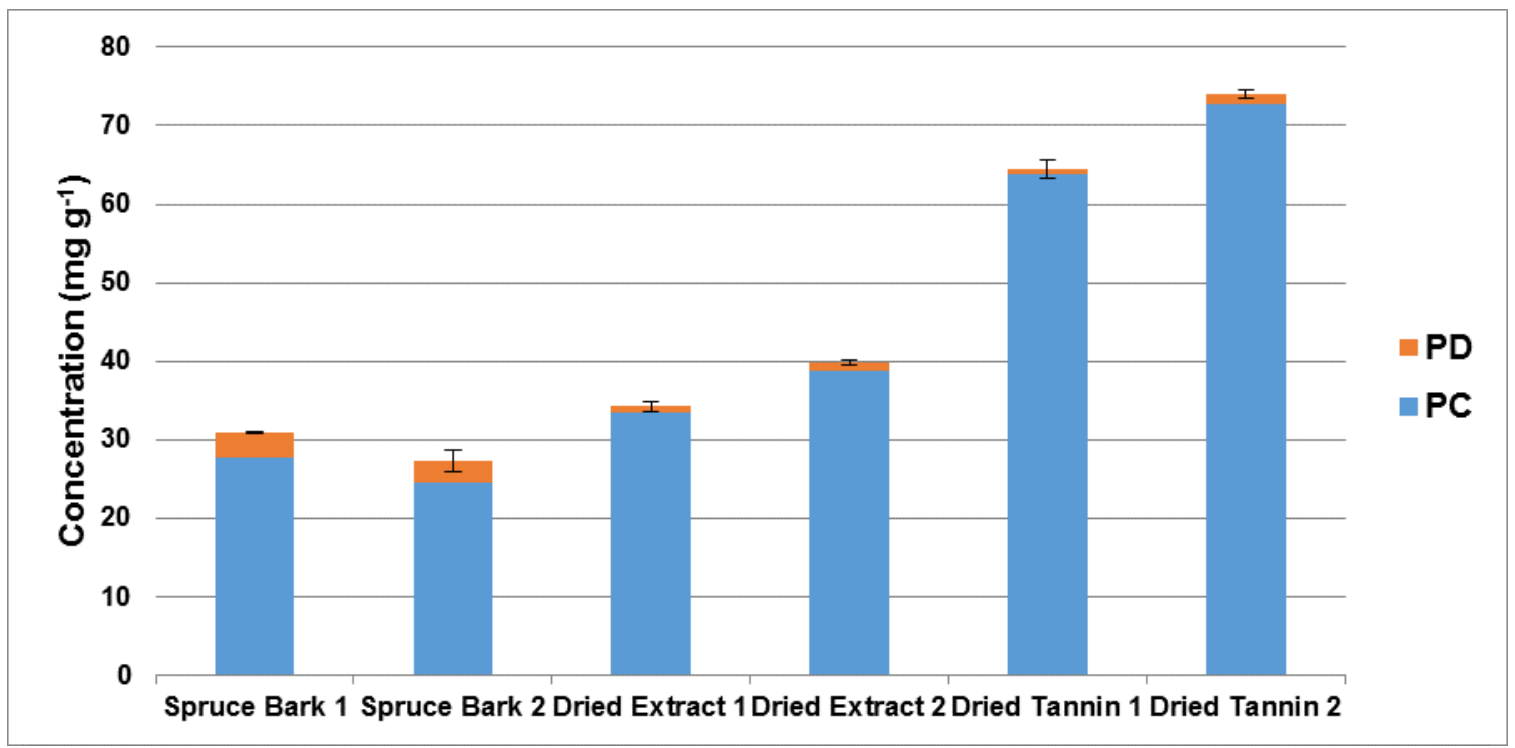

Fig. 3. Condensed tannins in samples of original spruce bark, dried hot water extracts, and dried XAD7HP treated extracts (dried tannins). $P D=$ prodelphinidins (structural units of (epi)gallocatechins), $\mathrm{PC}=$ procyanidins (structural units of (epi)catechin)

CT concentration in the extracts varied between 3.3 to $3.9 \%$ of the dry matter and was only slightly higher than in the initial bark, which indicates that hot water extraction was not very selective for CTs. Previously, Krogell et al. (2012) extracted tannins from Norwegian spruce bark with hot water, and the CT contents in the extracts were quite similar to the contents determined in the present study. Somewhat higher tannin content (6.6\% of dry matter) was reported by Bianchi et al. (2015) when they compared hot water extracts of barks of different softwood species. This is probably mostly due to different 
analytical methods applied. In the present study, CTs were determined by thiolysis and only proanthocyanidins, i.e., flavan-3-ol polymers, were included in the results while Bianchi et al. (2015) used total phenol assay (Folin-Ciocalteu) for quantification of CTs. They used thiolysis for qualitative analysis and they noted that only $26 \%$ of phenolics in Norwegian spruce bark extract were quantifiable by thiolysis indicating that the majority of the phenolics were actually not composed of proanthocyanidins. XAD7HP treatments roughly doubled the content of CTs in the extract and after treatments, the content varied between 6.5 to $7.3 \%$ of dry matter.

The pyrolysis products of Dried tannin 1 and Dried tannin 2 had a high amount of methoxyphenols, 36\% and 29\%, respectively (Fig. 4). The group, denoted as methoxyphenols consisted mainly of guaiacol derivatives, which are typical softwood lignin pyrolysis products (Kawamoto et al. 2014; Kawamoto 2017; Ghalibaf et al. 2019). Catechol derivatives are not only formed during lignin pyrolysis, but they are also typical tannin pyrolysis products (Ismayati et al. 2017; Pinto et al. 2019). Pinto et al. (2019) and Ismayati et al. (2017) confirmed this by model compound, namely catechin, pyrolysis studies. The main products from pyrolysis were catechol and 4-methylcatechol from the B-ring of catechin and epicatechin. The content of catechol derivatives, i.e. catechol and 4-methylcatechol, was $19 \%$ in Dried tannin 1 pyrolysate and 12\% in Dried tannin 2 pyrolysate.

A)
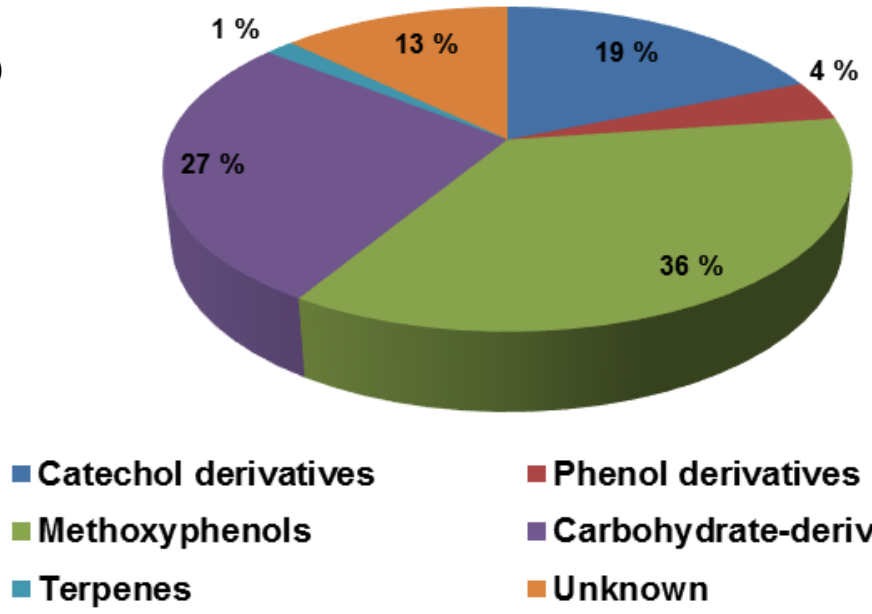

- Phenol derivatives

- Carbohydrate-derived units

-Unknown

B)

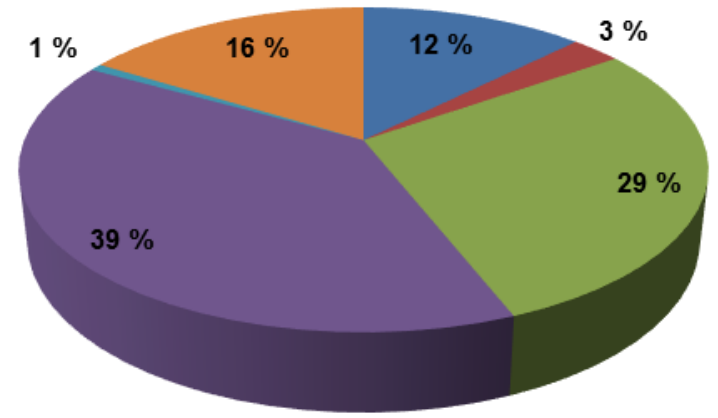

Fig. 4. Relative distribution of volatile compounds produced during Py-GC/MSD of purified (resintreated) and dried spruce bark hot water extracts. A) Dried tannin 1, and B) Dried tannin 2 extract.

Phenol derivatives, such as $p$-cresol are also typically formed in lignin pyrolysis. However, according to Pinto et al. (2019) also catechin pyrolysis produces a relatively high 
amount of different phenol derivatives. Thus, it is not possible to conclude which portion of catechol derivatives or phenol derivatives originate from lignin and which are formed due to the thermal degradation of tannins. Other phenolic extractives present in the extract complicate the issue further. The proportion of carbohydrate-derived products was also high, $27 \%$ and $39 \%$ for Dried tannin 1 and Dried tannin 2, respectively. This is in agreement with the chemical analysis results (Fig. 2). A small amount of lipophilic extractives, i.e., terpenes, was also detected in Py-GC/MSD studies. Based on these studies it could be concluded that the extract contained high lignin content as indicated by methoxyphenols in pyrolysate. However, the pyrolysis results are semi-quantitative which means that based on these results the amount of lignin could not be concluded. Py-THMGC-MSD results also confirmed the presence of lignin in the extract. In addition to carbohydrate- and lignin-derived units, 3,5,4'-trimethoxystilbene and 3,5,3',4'-tetramethoxystilbene were also detected.

\section{Specific Surface Areas and Pore Size Distributions of the Activated Carbon Foams}

According to the data obtained from the surface analysis, presented in Table 1, physically activated CFs derived from Dried tannin 1 and 2 had similar specific surface areas and pore volumes. PSD, calculated using DFT-model, shows that most of the pores created during the activation were in the microporous region, $88 \%$ and $94 \%$, and the rest of the remaining pores were in the mesoporous region. These results are in line with the results from the t-plot method using Harkins and Jura (1943) equations, as can be seen from Table 1.

Table 1. Surface Analyzes of Activated Carbon Foams Activated With Steam and Zinc Chloride

\begin{tabular}{|c|c|c|c|c|c|}
\hline \multirow[b]{3}{*}{ Calculation method } & \multirow[b]{3}{*}{ Unit } & \multicolumn{4}{|c|}{ Samples } \\
\hline & & \multicolumn{2}{|c|}{ Activating agent $\mathrm{ZnCl}_{2}$} & \multicolumn{2}{|c|}{ Activating agent steam } \\
\hline & & $\begin{array}{c}\text { Dried } \\
\text { tannin } 1\end{array}$ & $\begin{array}{c}\text { Dried } \\
\text { tannin } 2\end{array}$ & $\begin{array}{c}\text { Dried } \\
\text { tannin } 1\end{array}$ & $\begin{array}{c}\text { Dried } \\
\text { tannin } 2\end{array}$ \\
\hline \multicolumn{6}{|l|}{ BET } \\
\hline SSA & $m^{2} g^{-1}$ & 1275 & 1495 & 335 & 351 \\
\hline Pore volume & $\mathrm{cm}^{3} \mathrm{~g}^{-1}$ & 0.731 & 0.816 & 0.151 & 0.148 \\
\hline $\begin{array}{ll}\text { Langmuir } & \text { surface } \\
\text { area } & \\
\end{array}$ & $\mathbf{m}^{2} \mathbf{g}^{-1}$ & 1516 & 1783 & 362 & 383 \\
\hline \multicolumn{6}{|l|}{ t-plot } \\
\hline Micropore volume & $\mathrm{cm}^{3} \mathrm{~g}^{-1}$ & 0.169 & 0.18 & 0.11 & 0.121 \\
\hline Micropore area & $\mathrm{m}^{2} \mathrm{~g}^{-1}$ & 410 & 431 & 284 & 313 \\
\hline $\begin{array}{l}\text { External surface } \\
\text { area }\end{array}$ & $m^{2} g^{-1}$ & 865 & 1064 & 51 & 38 \\
\hline \multicolumn{6}{|l|}{ DFT } \\
\hline Pore volume & $\mathrm{cm}^{3} \mathrm{~g}^{-1}$ & 0.575 & 0.668 & 0.123 & 0.121 \\
\hline Micropores & $\mathrm{cm}^{3} \mathrm{~g}^{-1}$ & 0.361 & 0.425 & 0.108 & 0.114 \\
\hline Mesopores & $\mathrm{cm}^{3} \mathrm{~g}^{-1}$ & 0.213 & 0.243 & 0.015 & 0.007 \\
\hline Macropores & $\mathrm{cm}^{3} \mathrm{~g}^{-1}$ & 0.001 & 0 & 0 & 0 \\
\hline Micropores & $\%$ & 63 & 64 & 88 & 94 \\
\hline Mesopores & $\%$ & 37 & 36 & 12 & 6 \\
\hline Macropores & $\%$ & 0 & 0 & 0 & 0 \\
\hline
\end{tabular}

The chemically activated CFs, Dried tannin 1 and Dried tannin 2, with $\mathrm{ZnCl}_{2}$, had much higher specific surface areas and pore volumes than CFs activated with steam, as can 
be seen from Table 1. PSD of chemically activated CFs were different than in the case of steam activation. Up to 36 to $37 \%$ of pores were in the mesoporous region, but a majority of the pores, 63 to $64 \%$, were still in the microporous region according to the DFT-model.

\section{Compressive Strength}

As demonstrated in Fig. 5, the compressive strength of CFs made with Dried tannin 1 extract was much higher after the thermal treatment compared to the compressive strength of CFs made from Dried tannin 2 extract. The reason behind this finding can be due to the different compositions of Dried tannin 1 and Dried tannin 2 extracts. Pyrolysis of dried tannins showed that dried tannin 2 had a higher relative ratio of carbohydratederived compounds and less of methoxyphenols that could have an effect on the compressive strength. Overall tannin yield and concentration of CTs was higher in Dried extract 2, but there is no direct correlation between compressive strength and tannin yield of the extracts. A possible explanation of the difference in compressive strength after thermal treatment between the foams prepared from Dried tannin 1 and 2 can be due to the different amount of lignin or sugars inside the extracts, but there might be other possible explanations. Hot water extraction was performed higher temperature at $90{ }^{\circ} \mathrm{C}$ for dried tannin 2 than $70{ }^{\circ} \mathrm{C}$ extraction of dried tannin 1 . Hot water extraction temperature may have an effect on the quality of tannins but this needs to be confirmed with further experiments.

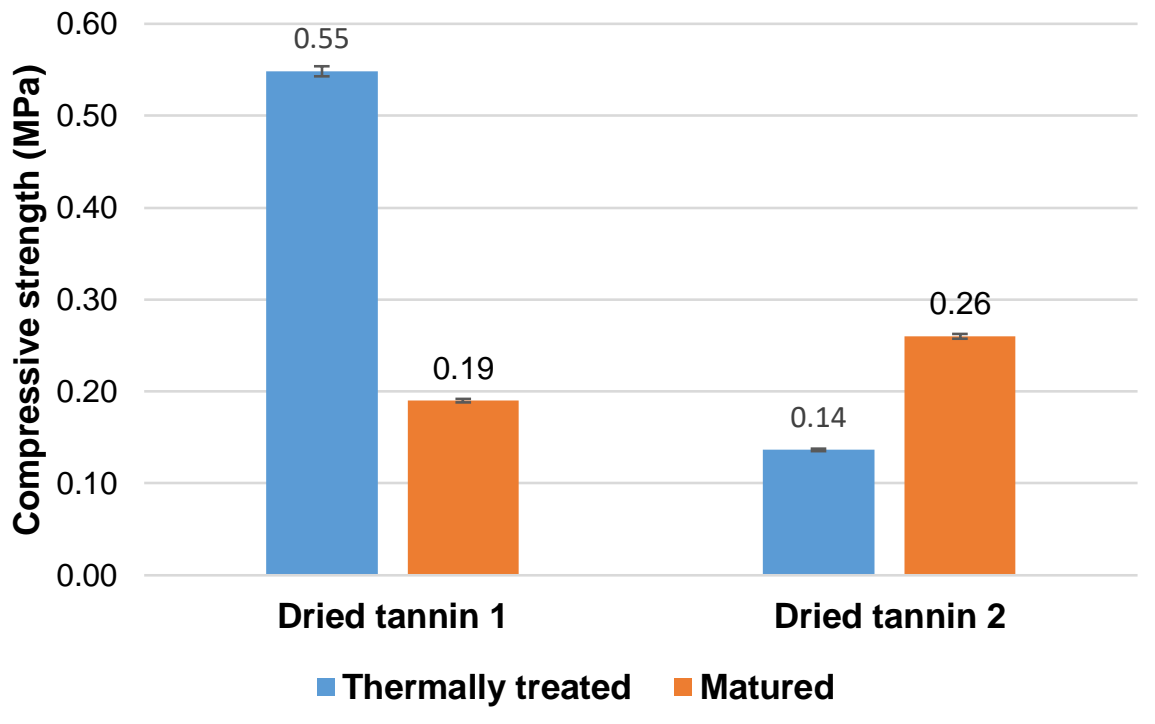

Fig. 5. Mechanical strength of the foams before and after thermal treatment

\section{Adsorption of Methylene Blue}

Activated CFs prepared from Dried tannin 1 and Dried tannin 2 extracts were tested in adsorption of methylene blue, and the results are presented in Fig. 6. Adsorption is highly dependent on the pore volume and especially on the mesoporosity of activated CFs. Results presented here are in good agreement with our earlier publication (Varila et al. 2019). Chemically activated CFs adsorbed methylene blue much more efficiently than steam activated $\mathrm{CF}$ due to the higher degree of mesoporous structure and higher pore volumes. 


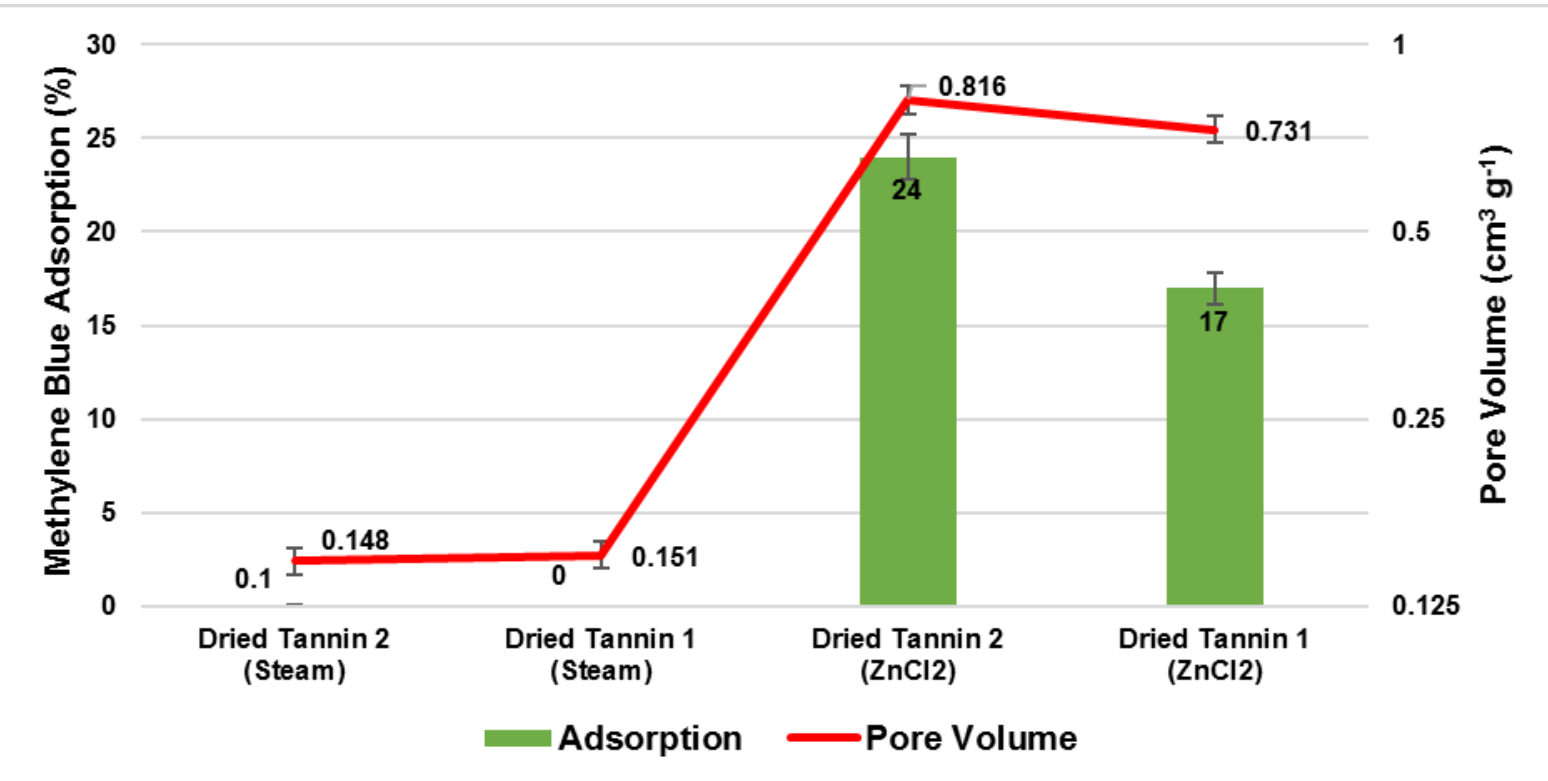

Fig. 6. Adsorption of methylene blue before and after activation procedures

\section{CONCLUSIONS}

1. The extraction of tannins from bark is a complicated process, and a number of cleanup steps are needed to produce clean tannins. Even if several cleanup procedures are used, the extracts obtained in this study appear to contain, besides the tannins, other compounds, such as sugars and lignin.

2. For the production of tannin-based carbon foams, tannins of high purity have normally been used. The results from this study indicate that crude tannin extracts containing sugars and lignin can be used for the production of carbon foams.

3. The foams produced can be further physically or chemically activated into activated carbon foams having tailored properties such as high specific surface area and welldefined porosity.

4. The compressive strength of carbon foams can be tailored to some extent with thermal treatment at high temperatures.

5. The adsorptive properties (measured with methylene blue) depend on the pore volume created inside the activated carbon foam structure during the thermal treatment.

\section{ACKNOWLEDGMENTS}

The authors thank Eelis Halmemies, Kalle Kaipanen, Jarkko Mäkinen, Jaakko Miettinen, Pauli Karppinen, Reetta Kolppanen and Satu Örling for skillful technical assistance in the laboratory and pilot experiments. UPM-Kymmene Oyj Pietarsaari is acknowledged for providing bark raw materials for the experiments. The authors also thank Annika Smeds for pyrolysis GC/MS analyses. Toni Varila would like to thank the Green Bioraff Solutions Project (EU/Interreg/Botnia-Atlantica, 20201508) for funding this 
research. Authors from Natural Resources Institute Finland gratefully acknowledge financial support from EU/Interreg/Botnia-Atlantica within the framework of Tannins for wastewater treatment (TanWat) project (20201484).

\section{REFERENCES CITED}

Alén, R. (2000). "Structure and chemical composition of wood," in: Forest Products Chemistry, P. Stenius (ed.), Fapet Oy, Helsinki, Finland, pp. 12-57.

Assarsson, A., Croon, I., and Donetzhuber, A. (1963). "Studies on wood resin, especially the change in chemical composition during seasoning of the wood, Part 2. Comparison of chip seasoning of spruce wood (Picea abies [Karst.]) with log seasoning," Sven Papperstidn. 69(16), 940-948.

Bianchi, S., Gloess, A. N., Kroslakova, I., Mayer, I., and Pichelin, F. (2014). “Analysis of the structure of condensed tannins in water extracts from bark tissues of Norway spruce (Picea abies [Karst.]) and Silver fir (Abies alba [Mill.]) using MALDI-TOF mass spectrometry," Ind. Crop. Prod. 61, 430-437. DOI: 10.1016/j.indcrop.2014.07.038

Bianchi, S., Kroslakova, I., Janzon, R. Mayer, I., Saake, B., and Pichelin, F. (2015). "Characterization of condensed tannins and carbohydrates in hot water bark extracts of European softwood species," Phytochemistry 120, 53-61. DOI:

10.1016/j.phytochem.2015.10.006

Brunauer, S., Emmett, P. H., and Teller, E. (1938). "Adsorption of gases in multimolecular layers," J. Am. Chem. Soc. 60, 309-319. DOI: 10.1021/ja01269a023

Buran, T. J., Sandhu, A. K., Li, Z., Rock, C. R., Yang, W. W., and Gu, L. (2014). "Adsorption/desorption characteristics and separation of anthocyanins and polyphenols from blueberries using macroporous adsorbent resins," J. Food Eng. 128, 167-173. DOI: 10.1016/j.jfoodeng.2013.12.029

Celzard, A., Zhao, W., Pizzi, A., and Fierro, V. (2010). "Mechanical properties of tanninbased rigid foams undergoing compression," Mater. Sci. Eng. A. 527, 4438-4446. DOI: 10.1016/j.msea.2010.03.091

Chemat, F., Vian, M., and Cravotto, G. (2013). "Green extraction of natural products: Concept and principles," Int. J. Mol. Sci. 13, 8615. DOI: 10.3390/ijms13078615

De Monte, C., Carradori, S., Granese, A., Di Pierro, G. B., Leonardo, C., and De Nunzio, C. (2014). "Modern extraction techniques and their impact on the pharmacological profile of Serenoa repens extracts for the treatment of lower urinary tract symptoms," BMC urol. 14, 63. DOI: 10.1186/1471-2490-14-63.

Ding, T., Bianchi, S., Ganne-Chédeville, C., Kilpeläinen, P., Haapala, A., and Räty, T. (2017). "Life cycle assessment of tannin extraction from spruce bark," iForest 10, 807. DOI: 10.3832/ifor2342-010

Ekman, R. (2000). "Resin during storage and in biological treatment," in: Pitch Control, Wood Resin and Deresination, E. L.Back and L. H. Allen (eds.), Tappi Press, Atlanta, USA, pp. 185-204.

Feng, S., Cheng, S., Yuan, Z., Leitch, M., and Xu, C. (2013). "Valorization of bark for chemicals and materials: A review," Renew. Sust. Energ. Rev. 26, 560-578. DOI: 10.1016/j.rser.2013.06.024

Ghalibaf, M., Lehto, J., and Alén, R. (2019). "Fast pyrolysis of hot-water-extracted and delignified Norway spruce (Picea abies) sawdust by Py-GC/MS," Wood Sci. 
Technol. 53(1), 87-100. DOI: 10.1007/s00226-018-1064.

Grand View Research (2017). "Tannin market analysis by sources (plants, brown algae), by product (hydrolysable, non-hydrolysable, phlorotannins), by application (leather tanning, wine production, wood adhesives), \& segment forecasts, 2014 - 2025," (https://www.grandviewresearch.com/industry-analysis/tannin-market.), accessed 22 January 2019.

Hackley, V. A., and Stefaniak, A. B. (2013). "' 'Real-world" precision, bias and betweenlaboratory variation for surface area measurement of a titanium dioxide nanomaterial in powder form," J. Nanopart. Res. 15, 1742. DOI: 10.1007/s11051-013-1742-y

Hammerbacher, A. Paetz, C. Wright, L. P., Fischer, T. C., Bohlmann, J., Davis, A. J., Fenning, T. M. Gershenzon, J., and Schmidt, A. (2014). "Flavan-3-ols in Norway spruce: Biosynthesis, accumulation, and function in response to attack by the bark beetle-associated fungus Ceratocystis polonica," Plant Physiol. 164, 2107-2122. DOI: $10.1104 /$ pp.113.232389

Harkins, W. D., and Jura, G. (1943). "An adsorption method for the determination of the area of a solid without the assumption of a molecular area, and the area occupied by nitrogen molecules on the surfaces of solids," J. Chem. Phys. 11, 431. DOI: $10.1063 / 1.1723871$

Holmbom, B. (2011). "Extraction and utilization of non-structural wood and bark components," in: Biorefining of Forest Resources, R. Alén (ed.), Paperi ja Puu Oy, Helsinki, Finland, pp. 178-224.

Ismayati, M., Nakagawa-izumi, A., and Ohi, H. (2017). "Structural elucidation of condensed tannin from the bark waste of Acacia crassicarpa plantation wood in Indonesia," J. Wood. Sci. 63(4), 350-359. DOI: 10.1007/s10086-017-1633-4

Kawamoto, H. (2017). "Lignin pyrolysis reactions," J. Wood. Sci. 63(2), 117-132. DOI: 10.1007/s10086-016-1606-z

Kemppainen, K. (2015). Production of Sugars, Ethanol and Tannin from Spruce Bark and Recovered Fibres, Ph.D. Dissertation, Aalto University, Espoo, Finland.

Khanbabaee, K., and van Ree, T. (2001). "Tannins: Classification and definition," Nat. Prod. Rep. 18, 641. DOI: 10.1039/B101061L

Kilpeläinen, P., Hautala, S., Byman, O., Tanner, L., Korpinen, R., Lillandt, M. K., Pranovich, A., Kitunen, V., Willför, S., and Ilvesniemi, H. (2014). "Pressurized hot water flow-through extraction system scale up from the laboratory to the pilot scale," Green Chem. 16, 3186-3194. DOI: 10.1039/C4GC00274A

Kotake, T., Kawamoto, H., and Saka, S. (2014). "Mechanisms for the formation of monomers and oligomers during the pyrolysis of a softwood lignin," J. anal. appl. pyrol. 105, 309-316. DOI: 10.1016/j.jaap.2013.11.018

Krogell, J., Holmbom, B., Pranovich, A., Hemming, J., and Willför, S. (2012). "Extraction and chemical characterization of Norway spruce inner and outer bark," Nord. Pulp. Pap. Res. J. 27, 6-17. DOI: 10.3183/NPPRJ-2012-27-01-p006-017

Lacoste, C., Čop, M., Kemppainen, K., Giovando, S., Pizzi, A., Laborie, M., Sernek, M., and Celzard, A. (2015). "Biobased foams from condensed tannin extracts from Norway spruce (Picea abies) bark," Ind. Crop. Prod. 73, 144-153. DOI: 10.1016/j.indcrop.2015.03.089

Lastoskie, C., Gubbins, K. E., and Quirke, N. (1993). "Pore size heterogeneity and the carbon slit pore: A density functional theory model," Langmuir. 9 (10), 2693. DOI: 10.1021/la00034a032

Link, M., Kolbitsch, C., Tondi, G., Ebner, M., Wieland, S., and Petutschnigg, A. (2011). 
"Formaldehyde-free tannin-based foams and their use as lightweight panels," BioResources 6(4), 4218-4228. DOI: 10.15376/biores.6.4.4218-4228

Matthews, S., Mila, I., Scalbert, A., and Donnelly, D. M. (1997). "Extractable and nonextractable proanthocyanidins in barks," Phytochemistry 45, 405-410. DOI: 10.1016/S0031-9422(96)00873-4

Mattila, P. H., Pihlava, J., Hellström, J., Nurmi, M., Eurola, M., Mäkinen, S., Jalava, T., and Pihlanto, A. (2018). "Contents of phytochemicals and antinutritional factors in commercial protein-rich plant products," Food Quality and Safety 2, 213-219. DOI: 10.1093/fqsafe/fyy021

Pash, H., Pizzi, A., and Rode, K. (2001). "MALDI-TOF mass spectrometry of polyflavanoid tannins," Polymer 42, 7531-7539. DOI: 10.1016/S00323861(01)00216-6

Pizzi, A. (2008). “Tannins: Major sources, properties and applications," in: Monomers, Polymers and Composites from Renewable Resources, N. M. Belgacem and A. Gandini (eds), Elsevier, pp. 179-199. DOI: 10.1016/B978-0-08-045316-3.X0001-4

Pfennig, A., Delinski, D., Johannisbauer, W., and Josten, H. (2011). "Industrial scale natural products extraction," in: Extraction Technology, H. Bart and S. Pilz (eds.), Wiley Online Library, pp. 181-220. DOI: 10.1002/9783527635122

Pinto, O., Romero, R., Carrier, M., Appelt, J., and Segura, C. (2018). "Fast pyrolysis of tannins from pine bark as a renewable source of catechols," J. Anal. Appl. Pyrol. 136, 69-76. DOI: 10.1016/j.jaap.2018.10.022

Raposo, F., De La Rubia, M. A., and Borja, R. (2009). 'Methylene blue number as useful indicator to evaluate the adsorptive capacity of granular activated carbon in batch mode: Influence of adsorbate/adsorbent mass ratio and particle size," J. Hazard. Mater. 165, 291-299. DOI: 10.1016/j.jhazmat.2008.09.106

Royer, M., Houde, R., Viano, Y., and Stevanovic, T. (2012). "Non-wood forest products based on extractives-A new opportunity for the Canadian forest industry. Part 1: Hardwood forest species," J. Food. Res. 1, 8. DOI: 10.5539/jfr.v1n3p8

Sandhu, A. K., and Gu, L. (2013). "Adsorption/desorption characteristics and separation of anthocyanins from muscadine (Vitis rotundifolia) juice pomace by use of macroporous adsorbent resins," J. Agric. Food Chem. 61, 1441-1448. DOI: 10.1021/jf3036148

Scalbert, A. (1991). "Antimicrobial properties of tannins," Phytochemistry 30, 38753883. DOI: 10.1016/0031-9422(91)83426-L

SCAN-CM 53:94 (1994)."Wood chips for pulp production. Wood content in the bark fraction," Scandinavian Pulp, Paper and Board Testing Committee, Stockholm, Sweden.

Seaton, N. A., Walton, J. P. R. B., and Quirke, N. (1989). “A new analysis method for the determination of the pore size distribution of porous carbons from nitrogen adsorption measurements," Carbon 27, 853-861. DOI: 10.1016/0008-6223(89)90035-3

Seidel, V. (2012). "Initial and bulk extraction of natural products isolation," in: Natural Products Isolation, Sarker, S.D., Nahar, L. (Eds.), Springer, pp. 27-41. DOI: 10.1007/978-1-61779-624-1

SFS-EN 14774-2 (2010). "Solid biofuels. Determination of moisture content. Oven dry method. Part 2: Total moisture. Simplified method," Finnish Standards Association, Helsinki, Finland.

SFS-EN 14775 (2010). "Solid biofuels. Determination of ash content," Finnish Standards Association, Helsinki, Finland. 
Tondi, G., and Pizzi, A. (2009). "Tannin-based rigid foams: Characterization and modification," Ind. Crop. Prod. 29, 356-363. DOI: 10.1016/j.indcrop.2008.07.003

Tondi, G., Zhao, W., Pizzi, A., Du, G., Fierro, V., and Celzard, A. (2009). "Tannin-based rigid foams: A survey of chemical and physical properties," Bioresource Technol. 100, 5162-5169. DOI: 10.1016/j.biortech.2009.05.055

Torvelainen, J. (2019). "Total roundwood removals and drain by region, 2018, (https://stat.luke.fi/en/total-roundwood-removals-and-drain-region-2018_en) accessed 13 January 2020.

Varila, T., Bergna, D., Lahti, R., Romar, H., Hu, T., and Lassi, U. (2017). "Activated carbon production from peat using $\mathrm{ZnCl}_{2}$ : Characterization and applications," BioResources 12(4), 8078. DOI: 10.15376/biores.12.4.8078-8092

Varila, T., Romar, H., and Lassi, U. (2019). "Catalytic effect of transition metals (copper, iron and nickel) of the foaming and properties of sugar-based carbon foams," Top. Cal. 62 (7-11), 764-772. DOI: 10.1007/s11244-019-01171-4

Varila, T., Romar, H., Luukkonen, T., and Lassi, U. (2019). "Physical activation and characterization of tannin-based foams enforced with boric acid and zinc chloride," AIMS Materials Science 6, 301-314. DOI: 10.3934/matersci.2019.2.301

Zhang, Q., Lin, L., and Ye, W. (2018). "Techniques for extraction and isolation of natural products: A comprehensive review," Chin. Med-UK. 13, 20. DOI: 10.1186/s13020018-0177-X

Article submitted: January 17, 2020; Peer review completed: March 14, 2020; Revised version received and accepted: March 24, 2020; Published: April 1, 2020.

DOI: 10.15376/biores.15.2.3651-3666 